\title{
LA COMEDIA MITOLÓGICA CALDERONIANA: SOBERBIA Y CASTIGO
}

\section{Introduccion}

Los mitos griegos constituyen pernanente fuente de inspiración, ya que sus posibilidades no se agotan en su primitiva significación histórica y religiosa, sino que se van actualizando siempre con nuevas facetas, al compás del desarrollo cultural e ideológico de cada época.

El poeta que revive las fábulas mitológicas no tiene que preocuparse de la invención del asunto, apenas nada del plan, ya que los personajes que intervienen, los acontecimientos que éstos deben vivir, sus amores y sus odios, el desenlace, todo ya está —en lo fundamental- prefigurado 1.

Lo que sucede es que el tema, las figuras mitológicas, perviven a través del tiempo. Hay una substancia que permanece inaltcrable; pero cada escritor, cada generación, cada época se han definido en su peculiaridad y han tomado conciencia de sí mismas enfrentándose $\mathrm{y}$ midiéndose con la Antigüedad. Cada una de estas aproximaciones, cada reencuentro - desde peculiares coyunturas históricas- ha sido un acontecimiento singular, lleno de novedades y de problemas. Las figuras mitológicas perviven; pero esta peremnidad no significa quietud, sino que - muy por el contrario- da lugar a múltiples interpretaciones y readaptaciones; los mitos helénicos pueden, pues, aplicarse como medida a las distintas épocas que los tratan ${ }^{2}$. Permanecen, perduran; pero dentro de una gran variabilidad determinada por las distintas perspectivas desde las cuales el mito puede ser visto y desarrollado.

2 José Marfa DE Cossfo, Fábulas mitológicas en España, Espasa-Calpe. Madrid, 1952, p. 4.

$\therefore$ LUIS DIEZ DEI CORRAI, La función del mito clasico en la literatura conlemipordinea; Gredos, Madrid, 1957, pp. 9, 76, 86, 87. 
Calderón se valió del tema mitológico en múltiples ocasiones. Se trata de mostrar cómo este dramaturgo, desde su peculiar perspectiva vital c histórica, se aproximó a las figuras mitológicas; cómo las actualizó,. reintcrpretó y readaptó a la circunslancia cultural del siglo XVII español.

Junto a estas consideraciones iniciales, debe destacarse que del conjunto de piezas nitológicas calderonianas se desprenden dos hechos bastante evidentes. Hay unidad temática y cronológica. La primera, obviamente, está determinada por el origen, por la procedencia. Tema, personajes, situaciones, conflictividad, provienen de la mitología. La otra se explica porque casi todas estas obras fueron escritas después de $165^{1}$; son, en consecuencia, creaciones de la última etapa de Calderón. Es el momento en que el insigne comediógrafo escribe autos sacramentales - para la Procesión del Corpus- y piezas cortesanas destinadas a entretener -mediante una compleja y variada acción dranática y una gran riqueza escenográfica- $a$ un público aristocrático encabezado, en muchas oportunidades, por los propios monarcas.

Aunque Calderón cscribió alrededor de quince comedias mitológicas, se pretende considerar por ahora sólo cuatro de ellas. Es posible encontrar un elemento unificador que justifica la elección. Los protagonistas -Ulises, Hércules y Anajarte- aparecen dominados por la soberbia y reciben, por esta falta, el castigo a que se hacen merecedores.

Esta aproximación se valdrá exclusivamente de un método intrinseco. Resulta evidente que observar estas comedias recurriendo a este único método limita y circunscribe bastante el campo de visión. Hay varios otros aspectos que merecerían ser considerados; valdría la pena detenerse, por ejemplo, a examinar el espectáculo teatral, el problema del destinatario, observar estas comedias en relación con la tradición mitológica desde el renacimiento al barroco, etc. Una investigación futura evidentemente tendrá que considerar estos y otros aspectos.

\section{Soberbia $y^{\circ}$ Castigo \\ I. Análisis dramático}

Hay un hecho que resulta evidente y que permite penetrar en este análisis. Aunque aparecen varios temas, es el amoroso el que se encuentra en todas estas comedias. Se desarrolla una casuislica amorosa y aparece

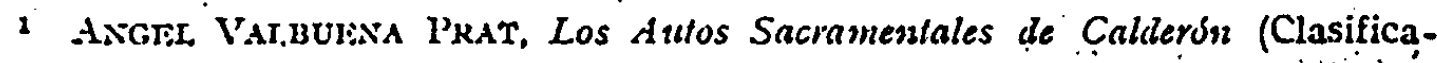
cionn y análisis). Reune IIispanique, 1924, LXI, pp. 54-56." 
como característico - siguiendu la terminología kayseriana - el motivo del triángulo amoroso. Lo más frecuente es que, en el desarrollo de la acción drannática, vayan apareciendo varias de estas situaciones típicas. No debe olvidarse la ley de subordinación tan característica del barroco y que consiste, como se sabe, en que las figuras secundarias dependen de la principal. Basta recordar, para ilustrar esta afirmación, los estudios sobre La vida es sueño que analizan las relaciones entre los diversos personajes. Esta ley, obviamente, también opera en la estructura dramática $\mathrm{y}$, siguiendo la idea anteriormente planteada, cuando hay varios triángulos amorosos, uno será el principal y el o los otros, los secundarios o subordinados.

- I a casuistica amorosa muestra estas posibilidades.

A. Escila y Caribdis tratan de conquistar el amor de Ulises. El motivo del triángulo amoroso se configura de un modo muy peculiar. I, frecuente es que sea el galán quien se esfuerce por conquistar el amor de alguna dama; en esta comedia la situación se invierte; ambas deidades tratan de conquistar el amor del griegn.

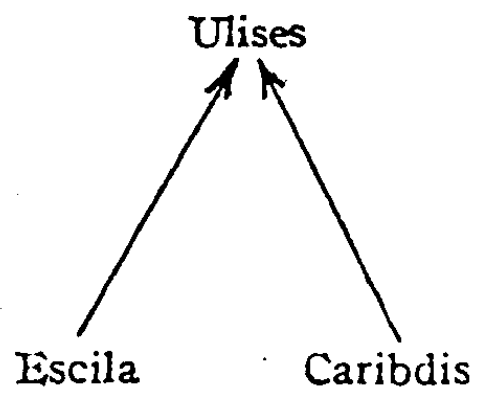

Las dos aparecen unidas por un objetivo común; pero muestran varios rasgos opuestos. Se mueven en esferas distintas; Escila, en la tierra; Caribdis, en el mar. Entran en competencia llevadas por el deseo de matar a los náufragos. Llegan a un acuerdo. La disputa la resolverá la experiencia. Usarán de sus cualidades. Escila se valdrá del hechizo de la vista; Caribdis, de los encantos de la voz ${ }^{2}$. Ambas usan cautela e industria. Se aprecia -y esto permite comprender más plenamente la configuración del conflicto dramático y del motivo literario-, que van a fingir amor a Ulises y que el objetivo profundo de su acción es destruir a todos los náufragos. Se da esta dualidađ, tan cara al barroco,

‘ I Pyopro Caldiónón de j.a BARCa, El golfo de las sirenas; I, p. 2157. Obras complelas, tomo I. Dramas. Iídición, prólogo y notas por el profesor ANGEr. VAJUUIENA 13RIONES. Aguilar, Madrid, 1959, $4^{3}$ crliciún. (Todas las otras citas por la misma edición.) 
de apariencia y realidad. Simulan un sentimiento, un afecto; pero la verdad es que buscan dar muerte a los griegos.

Debe considerarse otro hecho muy significativo. Ulises, con mucha presunción, dice que los sentidos fueron vasallos de la prudencia. Las dos deidades escuchan estas palabras y deciden comprobar si el galán está en lo cierto. Enuncian un acto de voluntad y se observa una clara oposición de voluntades. Escila y Caribdis están unidas por un común objetivo; ambas pretenden demostrar que Ulises, llevado por una exagerada seguridad en sí mismo, confía demasiado en poder dominar el imperio de sus sentidos. El héroe está en evidente peligro ya que la crueldad de ambos monstruos es reconocida por todos. Las dos se lanzan a la acción. Escila recurre a argucias muy propias de las damas de la comedia de enredos tradicional. Finge ser una mujer perseguida por una fiera. Sale cayendo y narra una falsa historia. El galán - llevado por una actitud heroica y caballeresca- se siente obligado a protegerla, a defenderla. Caribdis comenta la astucia, la habilidad de su rival. Lista, para impresionar a Ulises, se ha valido de su hermosura y de la laistima que una dama en apuros provoca en el ánimo'de cualquier varón. Caribdis no puede mantener una actitud pasiva. Comienza a cantar y Escila, que fingía un desmayo, se reanima muy prestamente tratando de que el griego permanezca a su lado. Ambas pugnan por atraer al galán. Ulises va perdiendo su seguridad, su confianza inicial. Comienza a sentir confusiones y dudas, ya que ambas hermosuras, la de la voz y la de la vista, lo atraen por igual. No sabe a cuál de las dos debe elegir:

\author{
De un mismo sentido entrumbas \\ equivocas os valeis. \\ Que no hay que ver dices tii: \\ confieso que verdad es, \\ habiendote visto a ti. \\ Tii dices que hay que oir: también \\ te lo confieso, pues hay \\ tu dulce acento; con que \\ concediendo a cada una \\ que hay que oir, mas no que ver, \\ me concedo a mi el dudar \\ lo que tengo de creer'.
}

Ulises decide, como única solución, huir. Escila y Caribdis se unen tratando de obstaculizar la fuga del galán. La competencia pasa a venganza. El griego triunfa y ambas deidades terminan arrojándose al mar.

1 El golfo de las sirenas; I, p. 2163. 
B. Ahora hay que examinar una situación repetidísinna; es la que puede designarse como el esquema de los sentimientos correspondidos.

- Debe hacerse una advertencia. Hay que buscar un modo de ordenar los conflictos amorosos. Parece el procedimiento más legítimo tomar como punto de referencia el conflicto principal. En El mayor encanto, amor, se desarrollan varios conflictos dramáticos. Aplicando el criterio recién señalado, se considera que hay reciprocidad sentimental porque el amor surge - después de muchas pugnas interiores- entre los protagonistas, entre Ulises y Circe.

El tema anoroso predomina a lo largo de la segunda jornada de esta comedia. Al término de la inicial los personajes principales han enunciado sus respectivos actos de voluntad. Ulises decide quedarse en Trinacria para dar libertad a todos los cautivos; para alcanzar esta propósito fingirá amor a Circe; ésta, por su parte, desea vencer al griego valiéndose de su hermosura, ya que no lo consiguió por medio de su ciencia ${ }^{1}$. Pero, desde los primeros diálogos de esta segunda jornacla, se aprecia que ninguno de los dos ha conseguido cumplir su decisión. Ha nacido un no declarado sentimiento amoroso. Ninguno reconoce su enamoramiento. Esta actitud va a caracterizar esta relación amorosa. A Circe su decoro, su honor, la impiden confesar su amor. Ambos enamorados van a caer en un ingenioso y ambiguo juego. Una vez más aparece el rasgo femenino de la astucia. La dama utilizará su industria amorosa para conquistar al galán. Busca una confidente y cómplice. Muy hábilmente, debido a que está enamorada de Lisidas, por lo cual no le puede ocasionar celos, elige a Flerida, quien, durante el día, deberá fingir amor a Ulises. Durante la noche, y sin que el galán se percate del cambio, podrá hablarle con toda libertad. Es la sagacidad femenina la que se ha puesto en acción, es, como dice la maga, la astucia que debe emplearse en esta cautelosa guerra ${ }^{2}$. Los personajes exteriorizan una galantería cortesana, finezas propias de la convivencia social; pero sus verdaderos sentimientos los encubren sistemáticamente. Sólo los apartes muestran lo que realmente pasa en su intimidad o, como sucede con Circe, cuando hace confidencias a su cómplice. En todas las otras ocasiones ocultan sus verdaderos afectos. Un solo ejemplo entre varios posibles. Ulises expresa palabras de alabanza a Circe; ella señala - a pesar del amor que siente- que él ha faltado al respeto que le debe. El griego se defiende $\mathrm{y}$ hace una distinción muy propia de la galantería del amor

1 Iil mayor encanlo, amor; I, pp. I606 y I608.

2 Idem anterior; II, p. IGro. 
cortés-caballeresco; distingue entre cortesana fineza y fineza amorosa. Circe, en un aparte, exclama: "Pluguiera a Dios que lo fuera!» ${ }^{2}$.

Sus palabras indican que ella hubiera preferido que las palabras fueran de amor y no simples cortesanas finezas, que es lo que él finge decir.

El conflicto amoroso sufre otra complicación. Hay un rival, Antistes, tambiéll enamorado de Circe, y que, llevado por justificados celos, trata de impedir ese amor. Por otro lado, Flerida también tiene problemas. Al simular que ama a Ulises provoca los celos, injustificados en este caso, de Arsidas. La situación amorosa llega a un grado de máxima ambigüedad cuando Antistes disimula su amor por Circe y Ulises finge amarla. Al término de la jornada casi todos los personajes encubren sus verdaderos sentimientos. Las relaciones personales son totalmente equivocas. Lo verdadero y lo falso, lo cierto y lo incierto, se entrecruzan borrándose, en más de una oportunidad, los límites.

Fl siguiente esquema trata de sintetizar la compleja situación conflictiva que esta comedia muestra.

Flerida

Debe disinular Amor correspondido

Lisidas

(Celos injustificados)

Circe

Amor correspondido

Lo disimulan
Finge amor

Amor verdadero

Io disimula

Al iniciarse la última jomada, el conflicto amoroso se ha resuelto. Circe y Ulises se han reconocido su amor y ella ha conseguido alejar a Arsidas.

C. Ahora es necesario considerar aquellas comedias que presentan una situación inversa; esto es, obras donde aparece el esquema de los sentimientos $n o$ correspondidos. Entre los personajes femeninos, Anajarte muestra una coustante actitud de desdén hacia los galanes y hacia el amor; entre los galanes, Hércules - protagonista de Fieras afemina amor- desprecia el amor de Yole; busca realizar las mayores hazañas $y$, llevado por su vanidad, recuerda sus grandes hechos heroicos. Todo lo que muestra de valeroso arrojo se corresponde con el profundo desdén que siente hacia las mujeres. Reitera una y otra vez su desprecio. Cuando

1 Idem anterior; II, p. IGII. 
Licas le sugiere ir en pos de las damas que acaba de proteger para que ellas tengan ucasión de agradecerle su acción, el héroe replica:

Yo más gracias no quiero del vencer, que el vencer ${ }^{1}$.

$\mathrm{Y}$ cuando se encuentra con Hesperia, agrega:

\author{
Dime \\ quien eres, bella deidad, \\ si es que yo ertiendo de bellas: \\ que para mit las hermosas \\ son solanente las fievas. \\ No fies \\ lii que por mujer le lenga \\ respeto, porque no hay \\ cosa que más aborrezca ${ }^{2}$.
}

Despućs, dialogando con el xey de Libia, reconoce yue no tiene lecciones de amor; agrega (fue sabe vencer, pero que no sabe amar y señala su punto de vista en forma categórica:

\title{
tengo a cualquier mujer \\ natural oposicions ${ }^{3}$.
}

Su actitud despierta el airado enojo de Venus y Cupido, que deciden castigar su soberbia. Para conseguirlo se valen de la hermosura de Yole. Hacen que la dama se le aparezca en sueños; después Euristio se la ofrece en matrimonio. Buscando eludir el problema, propone pastergar la decisión; pero en sucesivos apartes exterioriza sus verdaderos sentimientos:

$$
\begin{aligned}
& \text { ¿Cómo es posible, forluna, } \\
& \text { que en dos contrarios afcctos, } \\
& \text { aqui me persuada a amor, } \\
& \text { la que alli a aborrecimiento? } \\
& \text { ¡. . . . . . . . . . . . . } \\
& \text { condición mostrado el ceño! } \\
& \text { Mas iqué digo! iNo sabré } \\
& \text { vencerme a mi si a otros ienzo? } \\
& \text {. . . . . . . . . . . } \\
& \text { iAy de mi!, todo me abraso }
\end{aligned}
$$

\footnotetext{
J Fievas afeminza anor; I. p. 2040.

2 Idem anterior; I, pp. $2041-42$.

3 Idem anterior; I, p. 2048.

- Idem anterior; I, p. 2050.
} 
Hércules, sintiendo que sus fuerzas flaquean, sintiéndose incapaz de resistir la beldad de Yole, decide alejarse. Piensa que la distancia $y$ el tiempo le permitirán vencer esta inclinación.

Otros elementos van configurando la conflictividad amorosa. Yole recha\%a el posible matrimonio con Hércules. La presencia del galán le provoca horror; califica su semblante de fiero, y señala que se hiela - reflejo de su indiferencia - ante este pretendiente. Se lamenta de su obligación de casar:

\section{iOh nunca naciera antes que el arbitrio el rendimiento, $y$ entre respeto $y$ temor pasiera el honor ent mediol'}

Además, está la presencia de Anteo, enamorado de Yole, que ha conquistado el albedrío de la joven; pero ella no puede reconocer su preferencia afectiva. Para completar el planteamiento del conflicto dramático debe considerarse la presencia de Aristco, rey de Tesalia, que se lia ellamorado de Yole por medio de un retrato - motivo frecuente en la comedia tradicional española-, y que hace la guerra al rey de Libia. Finalmente debe señalarse - por la importancia que tendrá posteriormente- la hipocresía de este personaje. En un aparte reconoce que los desdenes de Hércules reflejan una actitud necia; decide servirse del valor y de la capacidad guerrera del héroe.

Esto es lo fundamental al término de la jornada inicial.

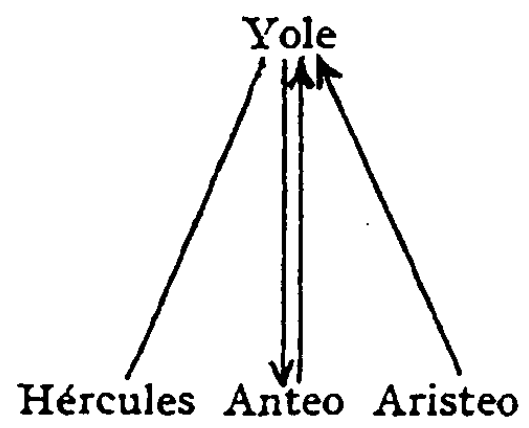

Es necesario destacar que la huida de Hércules significa, en cierto modo, un triunfo. Con su decisión, las fuerzas en pugna quedan paralizadas. Cupido tendrá que reactivarlas. Dice que aún tiene armas para vencer la soberbia del héroe. Ahora pondrá en juego otra: los celos. Licas informa a Hércules. El rey lo ha traicionado casando a su hija

1 Idem anterior; I, p. 2050. 
con Anteo. La acción sirve para que se cumpla el objetivo perseguido por Cupido:

¿Que fuera (jay de mi!) que fueran
celos, si huy celos, la brasa
quc enunellu en ccnizas no
se sabe que oculla arda.
hasta que desvanecidas
del soplo que las levanta,
lo que era ceniza es polvo
y lo que era polvo es ascua?
Pero ¿qué digo? iYo anor!
¡Yo celos! No es sino rabia
de la desestimación,
y ast, he de intentar vengarla'.

Se lanza a la acción. Se une con Aristeo. Ambos han sido agraviados. Iin la guerra mueren Eutistio y Anteo. La dama queda a merced del vencedor. A pesar de que éste exterioriza algunas dudas, decide aborrecerla; señala que nada - ni el espejo, ni la voz, ni el ingenio- serán capaces de vencer su enojo. Alora puede vengarse $y$, llevado por su ira, castigar a la dama. Pero, una vez más, intervienen las deidades. Cupido y Venus la aconsejan, debe fingir halago traidor:

... que él domestica las fiera.s. fieras afemina Amor.

Cupido sintetiza toda la estrategia:

Que él quiera y que no sea

querido es lo que quiero:

hállese más burlado

curanlo más satisfecho?.

Iole, siguiendo estos consejos, utiliza un recurso muy femenino: llorar fingiendo. El propio Hércules reconoce que el llanto es el mayor hechizo de la mujer. Lo que nadie habla conseguido, lo logran las débiles y tiernas lágrimas derramadas por la hipócrita dama que, en varios apartes, exterioriza sus deseos de venganza. Hércules cede, se ablanda. La astucia y la hipocresía triunfan. El héroe acepta a Yole como esposa; cae en sus lazos amorosos y olvida sus deberes y responsabilidades heroicas; debe elegir entre el amor y sus deberes guerreros. Yole trata

1 Idem anterior; I, 11). 2052-53.

2 Idem anterior; III, pl. 2066-67. 
de mantenerlo bajo su dominio; trata que la pasión amorosa persista hasta el momento de la venganza. Calíope trata de recordarle sus obligaciones. Hércules exterioriza una decisión:

Piérdase todo, y no lii,
que cs lo mus que hay que perder.
Callope, dile a dpolo
que si me oyo alguna vez
que sé vencer y no amar.
ya sé amzar y 120 vencer

Ha llegado la hora del castigo. Es el momento de la caída, la peor de todas, la caída por el ridículo. Aparece vestido con trajes femeninos, con trenzas y con una rueca. Postrado en tierra y llorando lo ven Aristeo, Licas y los soldados. Yole ha conseguido vengarse, ultrajar al héroe que termina reconociendo su derrota. Caliope canta:

$$
\begin{aligned}
& \text { "ca el tcatro del munudo } \\
& \text { tu trintifo, para que vea } \\
& \text { quicy quiso que las muijeres } \\
& \text { csclavas del hombre sean, } \\
& \text { que el es su esclavo, pues es } \\
& \text { csclavo de amor por ellas". }
\end{aligned}
$$

Conviene dar una mirada retrospectiva. El análisis de los conflictos amorosos lia mostrado los objetivos, los propósitos que guian a los personajes en sus acciones; las tensiones que se van creando; los obstáculos que dificultan el logro de sus objetivos; el dinamismo interior de la acción dramática; sus avances y retrocesos. Pero -además de estos aspectos de estructura interna- se muestra otro hecho importante. Los rasgos generales coinciden con los rasgos de la comedia de enredo de tipo palaciego. En éstas, como en las de Calderón, se encuentran una serie de elementos semejantes. Aparece el tema del amor en cualquiera de sus múltiples circunstancias y matices, secundado, casi siempre, por los celos. Amor $y$ celos constituyen partes integradoras del tema y ambas pasiones serán los resortes humanos y psicológicos fundamentales que motivarán la acción dramática dentro siempre de los imperativos de la cortesía y de la galantería. Además, los protagonistas son de la más alta nobleza y muchos de los recursos de que se valen, muchos de los enredos y equívocos que se desarrollan, corresponden a recursos utilizados en las comedias palaciegas. Los ejemplos podrían multipli-

\footnotetext{
1 Idem anterior; III, p. 2072.

2 Idem anterior; III, pp. $2075-76$.
} 
carse; pero resulta evidente que las comedias mitológicas calderonianas poseen rasgos semejantes a los de las comedias palaciegas. ¿Podría pensarse que no hay nada más? Iis decir, ¿podría creerse que éstas son piezas escritas simplemente para entretener a un público cortesano y que se quedan en puro juego escénico $y$ espectáculo? $O$, muy por el contrario, ¿es posible encontrar en ellas aspectos muy propios del teatro calderoniano?; vale decir, ¿es posible hallar la problemática tan esencial a Calderón?

\section{Soberbia y castigo}

Estas comedias muestran personajes cuyas decisiones, cuyos actos están determinados por la soberbia, por un exceso de confianza en el poder de su voluntad y de su razón. Hay en ellos una desmesura.

Por un lado, importa profundizar la actitud de Hércules y de Anajarte $y$, por otro, la de Ulises.

Ios dos primeros coinciden; desprecian el annor; sobrepasan los límites permitidos. Iil héroe, desde que aparece cn escena, exterioriza un profundo desclén y no titubea en ostentar su menosprecio. Recuerda cuando Aquiles viste trajes femeninos. Lo pone como ejemplo. Hasta esos extremos puede conducir el amor. Señala con mucha claridad su punto de vista:

¿Es annor mais que una ciega
tirama, a quien yo doy
las armas con que me venza?
¿Yo he de introducir en mi
otro yo, que con su fuerza
mande en mi mas que yo? '.

$\therefore$ Y cuando Hesperia le recuerda que Venus y Amor podrían vengar sus ofensas, replica:

¿Cómo ha de poder vengarlas

si yo no le doy licencia?

Egle reitera la posibilidad de la venganza $y$ el héroe persiste en su actitud:

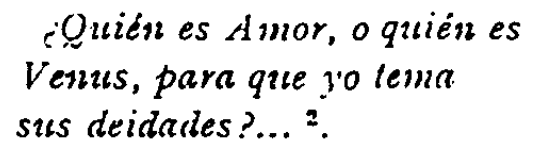

1 Idem anterior; I, p. 2044.

2 Idem anterior; I, p. 2045. 
Hesperia, a través de una seric de alusiones mitológicas e históricas, le recuerda el poder del amor; le hace notar que ha triunfado siempre; le pide recuerde a Julio César enamorado de Cleopatra; a Jasón, de Medea; a Teseo, de Ariadna; a Eneas, de Dido, y tantos otros ejemplos. Pero Hércules insiste:

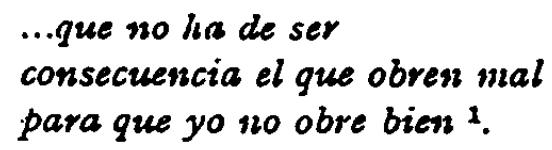

Esta desmesura, esta confianza exagerada, provoca la ira de ambas deidades, que deciden intervenir. El héroe, $\mathrm{y}$ tal como lo reconoce en varios pasajes, inicia la mayor de las luchas; señala el objetivo que persigue:

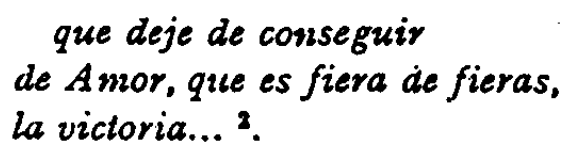

Se fornula preguntas tan significativas como ésta:

...¿No sabré

$$
\text { vencerme a int si a otros venzo? } 2 \text {. }
$$

$Y$, más adelante, la música -inientras ensalza las hazañas del personaje $\mathrm{y}$ alude a sus luchas interiores - repite en un verdadero leitmotiv:

$$
\begin{aligned}
& \text { ¡Ay de } t i ! \\
& \text { Que vencer a las fieras } \\
& \text { no es vencerse a si } 4
\end{aligned}
$$

Cupido anticipa el final con palabras que son la antítesis de las anteriores:

$$
\begin{aligned}
& \text {...ninguno vencerse } \\
& \text { pudo a si mesmo }
\end{aligned}
$$

Hércules lucha. El análisis dramático ya mostró sus tensiones y sus pugnas interiores. Logra triunfar en dos ocasiones. La primera,

1 Idesn anterior; III, p. 2070.

2 Idem anterior; II, p. 2062.

- Idem anterior; I, p. 2050.

- Idem anterior; II, p. 2062.

- Idem anterior; I, p. 2050. 
al sentir que Yole ejerce una atracción demasiado intensa sobre su voluntad, resuelve el problema huyendo. Con verdadera inteligencia, piensa:

\section{Pero el tiempo con la ausencia vencerd este devaneu".}

Después triunfa sobre los celos; pero es incapaz de vencer los falsos halagos, la hipocresía y, muy especialmente, las lágrimas de Vole. El - galán desdeñoso cae en las redes del amor; es su caída definitiva; hace todo aquello que antes censuró. Viste, tal como Aquiles, trajes femeninos $y$, perdido su albedrío y sin voluntad, sólo desea permanecer al lado de Yole. Termina, contemplado por todos, en una lastimosa y ridicula posición. El héroe capaz de vencer a las más feroces fieras; el héroe triunfador en todas las batallas, cae derrotado. Se hacen evidentes sus limitaciones. Fue un error el confiar tanto en su voluntad y en su razón. La desmesura inicial, su arrogancia han originado la caída. Debe someterse al amor, reconocer su poder; ha sido incapaz de triunfar sobre esta fiera, aparentemente poco temible, $y$, lo más importante, ha sido incapaz de vencerse a sí mismo. Es, en definitiva, el triunfo del amor y la caícla por la soberbia.

Cuando Anajarte narra su pasado, quedan explicadas las causas de sus desdenes amorosos. Al quedar huérfana, su tío, Argante, tomó posesión del reino de su padre. Sin atreverse a matarla, la ha dejado en aquella prision, en aquella sepultura. Dice que vive en un permanente delirio, en un constante frenesi, en un persistente letargo. Ella misma señala las consecuencias que la injusta acción ha tenido; descubre su intimidad:

\footnotetext{
Es el uno, que aborrezca (hecha ya desde nii tio a todos la consecuencia) de suerte a los hombres, que de humana sangre sedienta. vivo hidrópica, y el otro. que ya que vengar $n o$ pueda mi cólera en sangre humana, la vengue en brutos y fieras, bandolera ie stus grulas, pirata de siks cavernas ${ }^{2}$.
}

3 Idesn anterior; I, p. 2050.

2 La ficra, el rayo y la piedra; I, p. 1737. 
Sus palabras reflejan, con mucha intensidad, sus sentimientos, sus pasiones y explican sus actos. Rechaza a los hombres; rechaza el sentimiento amoroso; pero aún más, rechaza toda aproximación posible del amor a su vida, aunque sea a través de otros personajes. Cuando descubre que Pigmalión viene a su jardín porque se ha enamorado de La Estatua, que Céfiro adora a Irífile y que Ifis la ama a ella despide a aquella dama, ordena que saquen La Estatua del jardín y rechaza el amor de su enamorado. Sus propias palabras - cuando dice que vive hidrópica - son las que mejor definen su desmesura. Illa misma explica cl objetivo de su acción:

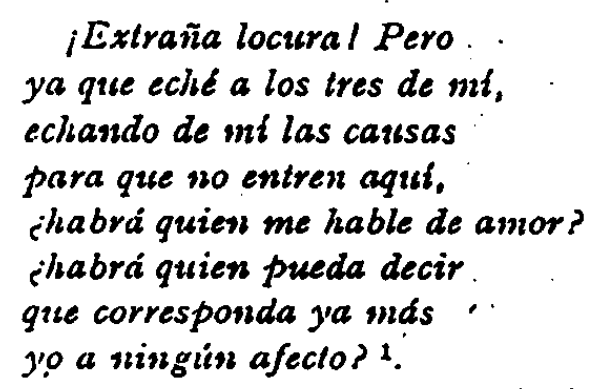

Ni la intervención de Anteros -el amor correspondido- la hace cambiar de actitud. La deidad baja a dialogar con la desdeñosa. Sus palabras señalan cuál debe ser la actitud de la dama y hacen evidente el error a que la han conducido su exagerada ira y sus deseos de venganza. Dice el dios:

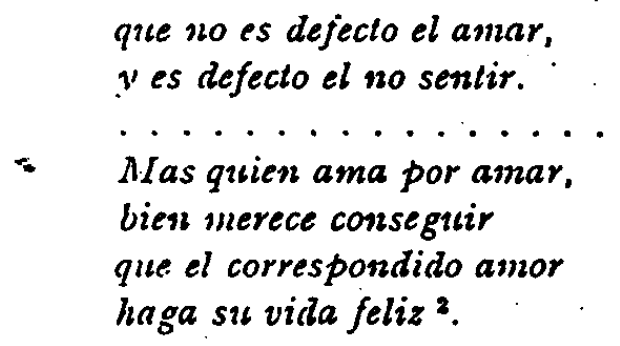

Pero Anajarte persiste en su posición. Su firme decisión la reflejan estas palabras:

Porque no has de persuadir musuca a mi pecho que deje de aborrecer's.

1 Ialem anterior; II, P. I750.

= Idem anterior; II, pl. $\mathrm{r} 759-60$.

3 Idem anterior; II, p. $1 ; 00$. 
La respuesta de la dama provoca la lástima del dios que, clarificando su posición, afirma que quien sentir no sabe, merece no sentir. Eilla insiste; señala que nació rayo. Anteros -anticipando el finalle recuerda que el rayo después es piedra. La soberbia de la dama es castigada. Il desenlace significa que todos deben someterse a las leycs del amor. Si alguien ama bien - puede pensarse en Ifis-, lo que merece es ser amado; sus sentimientos deben ser correspondidos. La mujer que no sabe querer, debe ser castigada por no acatar las leyes de la naturaleza y del amor. Anajarte se convierte en mármol. Anteros, cifrando en una idea su deseo, dice a Venus:

\section{Que quiesz no sabe querer}

sea mármol, no mujer ${ }^{1}$.

Sus palabras sintetizan el desenlace.

No hay que olvidar un hecho muy significativo. Lo predominante en el teatro y, en general, en la literatura española de los Siglos de Oro, es el desenlace feliz. Los amantes, después de salvar los más diversos obstáculos, llegan al amor y al matrimonio, legalización y santificación de aquél. En esta solución está implícito el principio renacentista que ve el amor como una concordancia que surge entre personas que se corresponden en la belleza física, en el sentimiento anoroso, etc. El amor - según señala Américo Castro ${ }^{2}$ - es visto como un principio armónico per se; $\mathrm{y}$, naturalmente, a los infractores de esta armonía acaecen las peores peripecias, les corresponden los mayores castigos. Puede verse la actitud de Hércules y de Anajarte desde esta perspectiva. Al rechazar el amor, infringen este principio de concordancia, de armonía y, por lo tanto, deben ser castigados. Conviene hacer otras consideraciones.

Anajarte coincide con muchas damas desdeñosas que aparecen en diversas comedias. Resulta interesante observar lo que otros personajes opinan sobre los desprecios femeninos. Hay que recordar que estas otras protagonistas terminan enamorándose; pero su actitud inicial es semejante a la de Anajarte. Varios personajes reiteran lo anti-natural del desdén femenino y señalan la obligación de amar que la mujer tiene. El Conde de Barcelona afirma que su hija está dominada por un cicgo desvario cuando ella se niega a casar y, en la misma comedia, cuando

1 Idem auterior; III, p. 1768.

2 Americo Castro, El pensamiento de Cervanles; Aladrid, Anejo VI de la $R F E, 1925$. 
Diana afirma que el desdén es natural a ella, Cintia, en un aparte, expresa una opinión diferente:

Que por error su agudeza
quiere el amor condenar,
$y$ si lo es, quiere enmendar
lo que erro naturaleza 1 .

En La vengadora de las mujeres, Lucela califica los desdenes femeninos de injustos:

...pres lo es

aborrecer a los hombres?.

Y en la misma conedia, Lisardo, que acaba de ver la beldad de Laura, comenta:

Que es belleza
sin igual, pero ofendida
de aguel rigor, que corriendo
liene a la Naluraleza.
Ser mujer y no querer,
contradice, aunque porfia
la humana filosofia ${ }^{3}$.

Esta postura es censurada por dos razones. Por un lado, se señala, en más de algún pasaje, la obligación social de la mujer, casarse. Pero, por otro, se destaca que la mujer no puede despreciar los galanteos, el amor de los varones. Diana exterioriza su punto de vista:

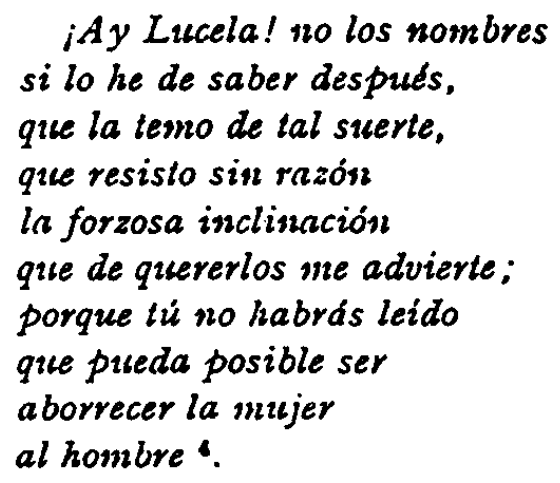

1 Agustin Moreto, El desdén con el desdén; I, 4. Comedias escogidas. B.AE, XXXIX. Coleccionadas e ilustradas por D. I, Uis FERnínDEZ Guirra y ORBE, Madrid, Atlas, 1950 .

- LOPE DE VEGA, La ventgadora de las mujeres; p. 1758. Obras escogidas, tomo I. Teatro. Estudio preliuninar, bibliografia, biografia, notas y apéndice de Fiberico Carlos SaINz di Robles, Madrid, Aguilar, 1958, 3." edición.

s Iden anterior; p. 1578 .

- Idem anterior; p. I58r. 
Y en la misma comedia, Julio se expresa en estos términos:

\author{
Bien sabe que la mujer \\ ha de apetecer el hombre \\ como la materia a la forma 1.
}

E1 propio dramaturgo expone, en esta comedia dedicada a la señora Fenisa Camila, su punto de vista... "Vanidad es en una mujer despreciar los hombres, pues cuando Aristóteles dijo que la mujer le apetecía como la materia a la forma, no pensó que era pequeño el encarecimiento" ${ }^{2}$.

Las citas son suficientes para mostrar dónde está la soberbia, la desmesura, el error de Anajarte. Los personajes femeninos terminan, invariablemente, enamorándose. Sólo ella persiste en su actitud. Va contra las leyes naturales y va contra su obligación dentro de la sociedad.

Hay que considerar las comedias en las cuales Ulises aparece como protagonista: El mayor cncanto, amor y El golfo de las sirenas.

En aquélla, el personaje es, durante toda la jornada inicial, el héroe triunfador, el héroe capaz de vencer todos los obstáculos y todos los peligros. Al iniciarse la acción ha logrado salvar del naufragio; ha conseguido derrotar las fuerzas del mar. Además, recordando las aventuras pasadas, enumera los triunfos alcanzados: Escila y Caribdis, Polifemo, las Sircnas. Cuando se enfrenta con Circe, desbarata sus hechizos. Antistes narra que todos sus compañeros han sido transformados en bestias. Ulises, gracias a que invoca la ayuda de Juno, consigue que Iris, la ninfa alada, traiga un ramillete mágico. Se produce el encuentro, el enfrentaniento del héroe con la hechicera. Es una dama desdeñosa. Para ella, los únicos delitos son los amorosos. Debido a que la divina hermosura de Flerida rindió su albedrio al amor de Lisidas, los castiga convirtiéndolos en árbol. Recibe a Ulises con palabras cortesanas. El griego coloca el ramillete en el vaso de néctar que le ofrecen; sale fuego y, sin titubear, amenaza a la maga con su espada; ella, muy asombrada, se rinde de inmediato:

Rendida tienes mi vida:

lasego de tu acero hoy

dos veces segura estoy,

por mujer $y$ por rendida ${ }^{3}$.

1 Idem anterior; pp. 1578-79.

2 Idem anterior; p. 1570.

2 El mayor encanto, amor; I, p. I603. 
Con esta acción logra que sus compañeros, que Flerida y Arsidas, recuperen su forma primitiva. Termina la jornada. Ambos personajes -Ulises y Circe- exteriorizan un acto de voluntad. Aquél, a pesar de las súplicas y de los consejos de sus compañeros, decide quedarse porque, según expresa en un aparte:

No fuera Ulises, si ya
que a estos montes he venido,
la libertad no trajera
a cuantos aqui cautivos
tiene el encanto. Hoy sere
de aquesta Esfinge el Edipo'.

$\mathrm{Y}$ agrega posteriormente:

Librare de aquesta fiera

a Triuacria, si amor finjo.

Circe exterioriza intenciones distintas:

Vencerdle mi hermosicra, pues mi ciencia no ha podido?.

Es el enfrentamiento; ambos tienen propósitos opuestos.

Todavía debe hacerse esta observación. La acción de Ulises está llena de peligros. Fa Iris lo previno. Al entregarle el ramillete, le puso una condición, una limitación importante. Ulises podrá vencer: "como al amor no te rindas" ${ }^{3}$.

Resulta, además, de fundamental importancia el relato de AntistesNarra lo sucedido; él $y$ sus compañeros penetraron por aquellos montes:
cuando a las varias forlunas
del mar pensamos que el cielo
nos habia dado amparo
nos habia dado puerlo:
mas jay triste!. que el peligro
es de mar y' lierra dueño.
porque en la tierra y el mar
tiene cl peligro su imperio".

1 Idem anterior; I, j. I 1006.

2 Idem anterior; 1, p. 1608.

- Idem asterior; 1, p. I (601.

- Jikem anterior; I, p. 1600. 
Caminando llegan hasta un pajacio hermosísimo; el narrador dice unos versos clarificadores: "la virtud no estaba en medio" ${ }^{\text {. }}$

Pronto salen bellisimas ninfas que agasajan muy delicadamente a sus huéspedes. Antistes vuelve a dar lo esencial de la situación $y$, además, llega a generalizarla:

Mirulió el deseo: mas icruind dijo verdad el deseo ${ }^{2}$.

Posteriormente, cuando sus compañeros son convertidos en brutos, comenta:

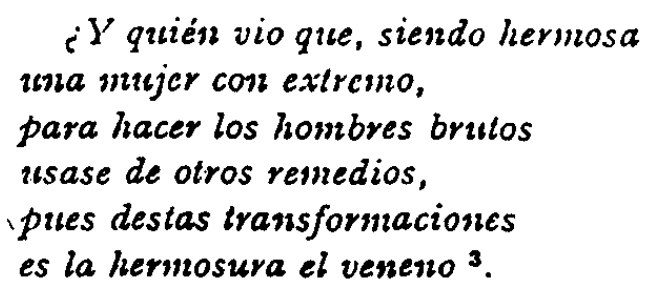

Muy importante resulta comprobar que en la otra comedia, El golfo de las sirenas, la valoración de la nuujer y de la hermosura se plantea en términos muy semejantes. Celfa identifica a la dama tras la cual el griego va; éste comenta:

\footnotetext{
Diciéndome que era Escila, me dices que puede ser traidora aquella hermosura.
}

La respuesta de la villana también generaliza la situación: "¿Qué hermosura no lo es?" 4.

Posteriormente, Alfeo identifica a la otra deidad, y Celfa vuelve a preguntar:

$$
\begin{aligned}
& \text { ¿A hora sabe su merced } \\
& \text { que el engañar con halagos } \\
& \text { lo hace cualquier mujers. }
\end{aligned}
$$

Las citas muestran los peligros que acechan al hombre en todas partes, en la tierra y en el mar; son los peligros de la hermosura, son los peligros del deseo, son los peligros que imperan en todo lugar donde

1 Idenn anterior; I, p. 1600.

2 Idem anterior; I, p. 1600.

3 I dem anterior; I, p. IGOI.

- IEl golfo de las sirenas; 1, p. 2163.

- Idem anterior; I, p. $2 \mathrm{IG}_{3}$. 
no existe 12 virtud. Antistes señala el medio de librarse. Consiguió huir antes de beber el néctar:

...corri; que enz efecto, el que se sabe librar de los venenos más fieros cle unza hermosura, es quien solo "niega los labios a ellos ${ }^{1}$.

Ulises está suficientemente prevenido. A pesar de todo, decide quedarse. Las razones son varias. Lo hace, en parte, llevado por su heroicidad; considera un deber librar a todos los que permanecen encantados en la isla. Además, está llevado por una excesiva confianza en sí mismo. Esta actitud ya se aprecia cuando Iris le entrega el ramillete:

\author{
Ya no liay que temer de Circe \\ los encantos, pues ya veo \\ lan de mi parte los hados. \\ lan en mi favor los cielos. \\ A sus palacios ine guia, \\ vercisme vencer eyz ellos \\ sits hechizos, y librar \\ a todos mis compañeros 2.
}

La misma confianza muestra Ulises en la otra comedia. En un pasaje mucho más significativo, expresa:

\author{
Siempre los senticios fueron \\ vasallos de la pritdencia, \\ y $n$ tienen contra mi. \\ ni vista $n i$ oido fuerza. \\ más que aquella que yo quiero \\ que livianannente terngan ${ }^{3}$.
}

Es el hombre tan seguro de su voluntad y de su razón, tan seguro de poder dominar sus pasiones, que cae en soberbia, cae en un orgullo desmesurado. Es la hybris que lo está dominando.

Resulta muy importante señalar una coincidencia. En ambas comedias, una vez que el protagonista ha emprendido la tarea que se ha propuesto, tiene un nomento de debilidad; hay un instante en que se

1 El mayor ancanlo, amor; I, p. IGor.

2 Idem anterior; 1,1 p. IGo2.

- El golfo de las sirenas; I, P. 2158. 
arrepiente de la decisión tomada. En El mayor encanto, amor, siente que la pasión amorosa lo está avasallando:

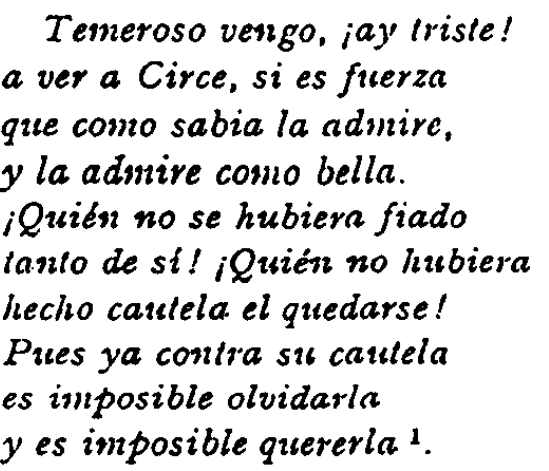

En la utra comedia, Danteo le recuerda que se declaró capaz de vencer a los sentidos; Ulises, lamentándose, replica:

$$
\begin{aligned}
& \text { iAy', que es facil de decir } \\
& \text { pero } 120 \text { fácil de hacer }{ }^{2} \text {. }
\end{aligned}
$$

Al iniciarse la última jornada de El mayor encanto, amor, Ulises la caído en las redes del amor. El acto de voluntad enunciado por ambos personajes al término de la jornada, no se cumplió. Ha nacido un recíproco amor que recién ahora se han reconocido. He aquí al héroe vencido por la hermosura femenina. Ahora se comprende mejor la estructura dramática y el sentido de la comedia. La jornada inicial muestra al héroe astuto $y$ valeroso; es el vencedor; ha vencido todos los obstáculos, a todos sus enemigos; es el héroe seguro de sí mismo, de su voluntad. De esta excesiva confianza nace su desmesura. En la jornada siguiente, Ulises ya se ha enamorado; pero resiste, todavía no reconoce su amor. En la última, vencido por la hermosura de Circe, vive en sus brazos, asistido por las damas de la hechicera. La situación conflictiva inicial se ha resuelto. Circe, muy hábilmente, ha alejado a su otro enamorado; ha conseguido dominar la voluntad del galán que vive exclusivamente para su amor. Ha eliminado todos los obstáculos. Hay un pasaje que refleja la enajenación mental en que Ulises vive. Despierta en el momento que Circe está en una batalla y, nuy asombrado, se pregunta:

$$
\begin{aligned}
& \text {...Solo estoy. } \\
& \text { ¿Pues cómo sin Circe pude } \\
& \text { vivir un insiante?... }{ }^{3} \text {. }
\end{aligned}
$$

1 Ill mayor encanto, amor; II, p. I 6 ro.

- IEl golfo de las sirenas; I, p. $216_{4}$.

3 El mayor encanto, amor; III, p. IG29. 
Anuladas todas las fuerzas, anulados los impedimentos, será necesario que otros personajes tomen nuevas decisiones que puedan crear una nueva conflictividad. Son los companeros de Ulises quienes procuran salvar a su jefe. Antistes recuerda todo lo sucedido:

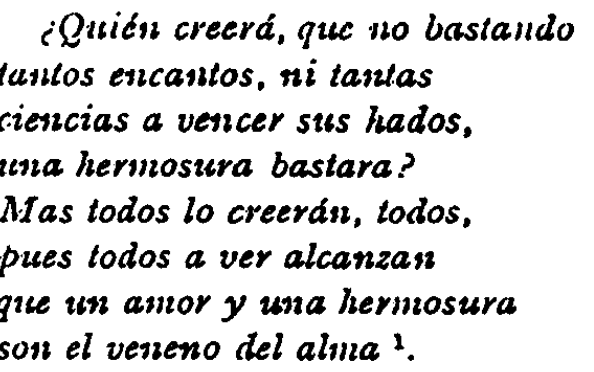

Pasaje fundamental. Ulises ha sido vencido por la hernosura fenenina; pero lo más importante es que Antistes generaliza; lo sucedido al griego no es un hecho aislado, no es una caída individual, personal; sino que lodos - palabras que en dos versos reitera en tres ocasiones-, cstán sometidess a la fucrza avasalladora de la belleza femenina y de la pasión amorosa. Antistes ha pensado una traza:

$$
\begin{aligned}
& \text { con que a su olvido le acuerde } \\
& \text { de su honor y de su fama? }
\end{aligned}
$$

La argucia decisiva la ejecuta mientras Circe guerrea. Ulises duerme. Pone a sus pies las armas de Aquiles. Al despertar sufre una fuerte impresión que se hace intensísima cuando, abriéndose una boca de la que sale fuego, Aquiles le habla desde las profundidades. Lo trata con gran dureza; lo califica de afeminado griego, y agrega:

\footnotetext{
$A$ cobrar vengo mis armas, porque el amor 130 las jutzgue ya de sut templo despojo. torpe, olvidado e intitil: porque $n$ quieren los dioses que otro dueño las injurie. sizo que en mi sepultura a par de los siglos dureti ${ }^{3}$.
}

Aquiles le recuerda sus responsabilidades; le indica que debe volver a surcar los mares y que, si asi no lo hace, el castigo será implacable.

1 Idem anterior; III, p. 1622.

3 Idem anterior; III, p. 1622.

3 I dem anterior; III, p. I6.30. 
Ulises se desespera; siente asombro y horror; su desconcierto es tan profundo que cncuentra una única solución, escapar:

Iltyamos de aqul; que huy

es huir accioun ilicstre,

piecs los encrizlos de amor

los veruce ayruél que los huye:

y disculpándose agrega:

Hermosa Juno, no culpes
el mayor encunto, amor,
pues aungue tus flores inue
pude vencer mil encantos,
y aqueste solo no piule.

Después dice los versos más significativos; los que contienen la clave de todo lo sucedido; los que reflejan lo esencial de toda la conflictividad:

Del mayor culciato, : anum

la razún me sacú libré2.

¡Por fin el héroc ha logrado vencerse a sí mismo! ¡Por fin se ha librado de la enajenación amorosa! Circe, desesperada, derrotada, desaparece. Todo se destruye. Quedan en libertad todos los espiritus que la maga tuvo presos:

...Eslos palacios, que mágico el arte finge, desvanecidos en polvo solo una voz los derribe ${ }^{3}$.

Resulta esencial destacar que en la otra comedia el desenlace es muy semejante. Ulises llega a la misma solución:

Huir de aqui, que estos contrarios huyendo se vencen ".

Escila y Caribdis, también derrotadas, desaparecen y todo el lugar donde ellas habitaban.

Hay varias expresiones que sintetizan la posición del barroco ante una de las cuestiones esenciales de la creación artística. Su finalidad

1 Iden anterior; III, pp. 1630-31.

2 Idem anterior; III, p. I63I.

2 Iden anterior; I11, p. I632.

- El golfo de las sirenas; I, p. $216_{4}$. 
la condensan términos como enseñar $y$ deleitar juntamente o deleitar aprovechando. En las comedias mitológicas calderonianas hay muchos elementos que están allí para conseguir el deleite de los espectadores; (')tre otros, la rique\%a escenográfica, la búsqueda de variedad, los ingeniusus enredos de la trama, las intervenciones del gracioso, etc. Pero, además, se pretende cnseñar. Puede afirmarse que uno de los nexos que unen la Contrarreforma con la literatura barroca es su preocupación moral, sin olvidar la influencia aristotélica - bastante estudiada, entre otros, por Hatzfeld-, que determina la perfección estética que caracteriza estas obras y la tendencia a la ejemplaridad. Esta propensión a mostrar casos ejemplares es la que se encuentra en Ulises y Hércules. La intención resulta bastante evidente. El drama de ambos está determinado por una antinomia, por un dualismo interior; sufren la pugna entre la razón y la pasión; la grandeza de ambos se muestra en esta lucha. Podrán salir vencedores o vencidos, según sean capaces de dominar o no sus pasiones; pero lo que los engrandece es el esfuerzo desarrollado. Essta dualidad es consustancial a la naturaleza humana; dualismo que puede aproximar al hombre al estado de gracia, a los ángeles o puede conducirlo a la miseria del estado de culpa que lo pone al nivel de los brutos. Si el hombre quiere elevarse, si desea buscar y alcanzar la trascendencia, debe - según la enseñanza moral del barroco-, apartarse, alejarse de toda mundanidad, ya que su fin no está en los objetos materiales, ni en los caducos valores terrenales, sino en tratar de alcanzar el camino que lo conduzca a Dios. Esta búsqueda es la esencia, es la que define el papel del hombre en este mundo. Evidentemente, tiene que luchar con sus propias limitaciones; es la consecuencia natural de la contingencia humana, de ser hombre. En un auto sacramental, El diablo mundo, se lee:

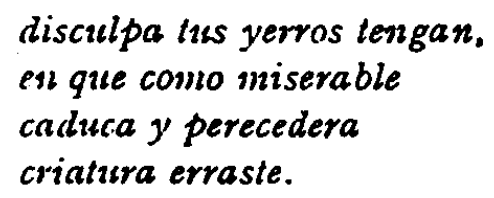

$Y$ en La nave del Mercader, mientras se abre un peñasco y se ve al Hombre, dormido y vestido de pieles, y al Deseo despierto, el Amor dice:

Ll Hombre tras sa Deseo va, forgoso es su peligro.

El hombre vive en una permanente lucha entre sus deseos y sus apetitos -inclinaciones ciegas del hombre-, y la razón y la voluntad. 
El entendimiento es la capacidad ordenadora y de elegir que posee; la voluntad es la capacidad de poder. Aquél tiene como finalidad buscar y alcanzar la verdad y es preeminente entre todas las facultades. Debido a que tiene una capacidad limitada, necesita valerse de los sentidos. Calderón reconoce la primacia al Oído, como sentido que no se fía de las apariencias. Es tópico en este dramaturgo el tema de que los sentidos sólo son capaces de captar accidentes y permiten juicios engañosos. Los sentidos de por sí son nobles; pero el hombre usa mal de ellos. La soberbia, que es pecado del entendimiento, puede conducir al hombre a la caida. Hechas estas consideraciones puede volverse a los personajes mitológicos, a Ulises y Hércules.

Resulta bastante evidente la intención ejemplar que la caida de ambos héroes tiene. No son unos personajes vulgares, sino verdaderos símbolos del valor, de la heroicidad. Eillos, que han sorteado los mayores peligros, que han vencido siempre, son derrotados por las armas femeninas, por la hermosura y por los falsos halagos. Iil orgullo los ha extraviado en la encrucijada del Bien y del Mal. Ja imaginación, los sentidos y el egoísmo son los tres fundamentos del Mal $\mathrm{y}$ los tres obstáculos que impiden ver claro y escuchar a la razón; son los tres medios de que se vale el demonio para engañar al hombre. Ulises, en El golfo de las sirenas, es aturdiclo por los sentidos de la vista y del oído, de los que son agentes externos las figuras de Escila $y$ Caribdis. En la otra comedia, el amor también penetra a través de los sentidos; es la hermosura de Circe la que vence al héroe. En ambos casos, es la representación de los trabajos que ha de sufrir el alma para librarse de la tiranía de los sentidos cuando están excitados por la pasión. La doctrina de Santo Tomás resulta adecuada para explicar la soberbia que domina a Ulises. «Se trata de la relación entre soberbia, razón, apetito racional (voluntad) y apetito sensible (especialmente irascible): "un acto puede pertenecer a un vicio de tres maneras: directamente, de modo antecedente y de modo consiguiente... a la soberbia pertenece directa y como esencialmente el deseo inmoderado de la propia excelencia; de modo antecedente el que alguien se estime hasta el punto de creer que le corresponde semejante excelencia; y de modo consiguiente, el que se expresa por medio de palabras y acciones ostentosas derivadas de esta estimación y deseo. De estos tres modos del vicio de la soberbia, el primero pertenece al apetito irascible y los otros dos a la razónn ${ }^{1}$. De forma antecedente co-

1 Anger, L. Cilvirit, El significado de "La vida es squño". Valencia, Albatros, r97r, pp. 98-99. 
rresponde, en el caso de Ulises, a que se estima exageradamente. Essta actitud se aprecia cuando considera que le corresponde la misión de salvar a todos los personajes hechizados por Circe, o cuando desoye los prudentes consejos de Antistes, o cuando confía en poder doninar sus sentidos. I a otra, la de modo consiguiente, se manifiesta en las palabras ostentosas que, en más de una ocasión, exterioriza y que son reflejo de su autoestimación excesiva, de esa alta idea que ticne de sí. Estos dos modos del vicio de la soberbia pertenecen a la razón. El hombre, al ser dominado por una pasión, tiene nuuchas dificultades para apartar de su imaginación las cosas que la originan $y$, por esta causa, el juicio de la razón sigue casi siempre la pasión del apetito sensible. Esto explica, en buena medida, la enajenación en que Ulises vive al tener siempre presente a Circe, desentendiéndose de todas sus otras responsabilidades. Su acto tiene significación moral, ya que es un acto voluntario; todo acto de virtud o de pecado es voluntario. Debe destacarse que el defecto moral no radica en el apetito carnal, sino en la sujeción de la razón a éste. Se origina, mediante este defecto, una desarmonía en las relaciones entre las facultades intelectivas y la parte sensible del hombre; se debe al hombre mismo, quien, permitiendo que dentro de su propio yo se produzca tal desorden, avanza hacia el reino de la ignorancia y del vacío moral.

Ambos héroes padecen una intensa lucha interior; soportan vacilaciones, dudas; pero caen derrotados. La soberbia ha determinado que, al perder el dominio de la razón y de la voluntad, sean incapaces de alcanzar el gobierno de sí mismo. En esta lucha psicológica, caen en la oscuridad, son dominados por sus afectos y apetitos. La hermosura penetra por los sentidos; pero el entendimiento y la voluntad son los que han fallado; han elegido erradamente; se han decidido por lo aparencial, por una belleza caduca, perecedera, finita. Al final, con la caída, surge la luz. Es el claroscuro metafísico. El hombre -librado de las pasiones, recuperado el equilibrio interior por medio del sufrimiento que lleva al predominio de la razón y de la voluntad-sale de la oscuridad a la claridad. Es la catarsis en sentido barroco. El hombre se libra del poder de las pasiones y llega a la práctica de la virtud; ha sido capaz, después de un largo camino de luchas interiores, de vacilaciones $y$ de dolores, de superar sus malas inclinaciones y de despertar las buenas. Del caos, de la confusión, del claroscuro en este mundo y en el alma, surge una deslumbrante claridad, la de la verdad. Ulises, al adquirir conciencia de su error, de su enajenación mental, al sentir que ha caído, logra vencerse a si mismo - solución muy calderoniana-, y huye. Hércules, en cambio, se da cuenta de sus debilidades y flaquezas, reconoce 
que el amor to ha vencido. Termina derrotado. Es el héroe vencido por medio del ridículo.

La validez de toda la interpretación hecha la corroboran las palabras de Ulises ya citadas:

Del mayor celcanto, amor la razón me sacó libre.

Estos versos sintetizan toda la problemática; no sólo la de este héroe, sino en general la del hombre. La naturaleza humana opera convenientemente cuando está dirigida por la razón que es la potencia ordenadora; pero cuando cae en hybris, conduce al caos hasta que, modificado el rumbo o eliminado el elemento discordante, el orden rige nuevamente la vida. Es el claroscuro metafísico tan típico del pensamiento calderoniano y tan propio del barroco hispánico. Es, en sintesis, el hombre que, luchando consigo mismo y a través de la purificación, a través de la catarsis que ocasiona el sufrimiento, consigue una armonía interior.

N. IERWin Haverblick Ojeda 